\title{
Experimental Study on Discharge of Model Silo with Different Ratio of
}

\author{
Height to Diameter \\ ZhirongZhang ${ }^{1, a}$ FangYuan ${ }^{2, b}$ ZhijunXu ${ }^{3, c}$ JiahaoChen ${ }^{4, d}$ \\ 1.Henan University of Technology, China; \\ 2.Henan University of Technology, China; \\ 3. Henan University of Technology, China; \\ 4. Henan University of Technology , China; \\ a243581099@qq.com, ${ }^{\text {b879304369@qq.com, }{ }^{c} 24594620 @ q q . c o m,{ }^{d} 1142653303 @ q q . c o m}$
}

Keywords: Safety of silo, Wall discharge, Dynamic pressure, Overpressure coefficient, Scale test Abstract: The safety problem of silo has been the main problem in the world. When the wall is discharged, The dynamic pressure of the material on the silo wall is the main reason which leads to the destruction of the main body and the hidden trouble. Based on the datum from model test of silo, this paper mainly will employ the method of scale model test to study the influence of the dynamic lateral pressure changes and over-pressure coefficient of material in warehouse for two models of different height diameter ratio.

\section{Introduction}

With the rapid development of industry and agriculture, the silo is widely used in various fields. As the main type of grain circulation in the world, the dynamic lateral pressure of the material in the silo wall is the main problem to be solved. Among them, the study of the silo pressure theory, especially the dynamic pressure caused by the flow of the stored material, is a subject of great concern in China and other countries. At present, many experts and scholars at home and abroad have studied and demonstrated the lateral pressure of silo. Tu Juxian studied a deep silo model with organic glass, the result shows that the maximum lateral pressure of the silo wall occurs at the junction of the two flow types rather than at the root of the silo. C.J.Brown used square bin model experiment, material is soybean and sand,and the stress strain relationship of silo in loading,discharging and storage is obtained. He found the stiffness of the wall has a great influence on the distribution of lateral pressure, and there are different stress state during the loading and discharging.This paper combined the existing researches, based on the model test, the results of dynamic lateral pressure of two models with different height to diameter ratio are analyzed.

\section{The design and test methods of model silo}

The test process, depending on the height-diameter ratio of silo models were divided into two groups shown in the Fig.1 and Fig.2. In Fig.1, the maximum storage height of silo wall was $1.1 \mathrm{~m}$, inner diameter was $1.0 \mathrm{~m}$; in Fig .2, the silo wall height was $1.1 \mathrm{~m}$, the maximum storage height was $1.1 \mathrm{~m}$, inner diameter was $0.5 \mathrm{~m}$; the material was organic glass. Its main physics parameters are elastic modulus is $2.758 * 10^{3} \mathrm{MPa}$, thermal expansion coefficient is 0.000033 , the Poisson's ratio is 0.29. This paper used direct measurement to get the lateral pressure data by using the instrument for resistive soil pressure sensor which the size range is 0-0.01 $\mathrm{MPa}$. The resistive soil pressure sensors were divided into three groups named $\mathrm{A}, \mathrm{B}$ and $\mathrm{C}$, which were installed on seven different measuring points. 
In this experiment, the dynamic pressure test was carried out by using different discharge methods in models. In plan A, opened the unloading port A on the side wall, recorded the different depth strain-stress curve under unilateral discharging; In plan B, opened the two sides of the discharging ports, observed and recorded the strain-stress curve on each measuring point under bilateral discharging.

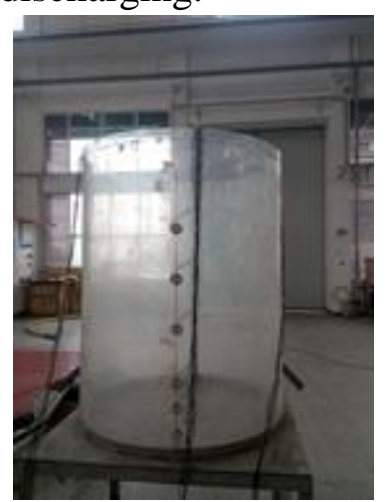

Fig.1 Model silo 1

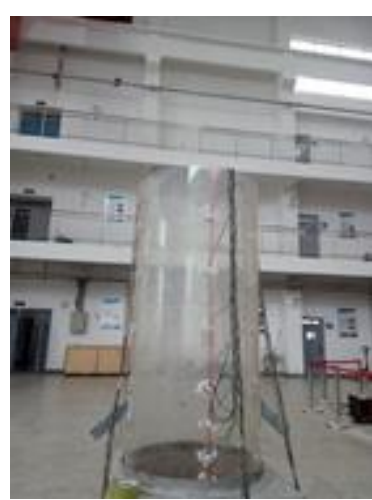

Fig.2 Model silo 2

\section{Analysis of unloading test results of two model cartridge wall}

Through 6 groups of dynamic pressure tests, the dynamic pressure and overpressure coefficients in $\mathrm{A} \& \mathrm{C}$ groups during the unloading period of two models with different height-diameter ratio is analyzed. Through the dynamic test, the six groups of test data from different angles are compared and analyzed, the static side pressure value of the tube wall at different depths is selected according to the average of the test points in the static pressure test, the choice of dynamic side pressure value is the maximum value of each measurement point in each group of dynamic discharge test.

\section{Analysis on results of single side discharge test of tube wall}

Table 1 The results of single side discharge of group A for two silo models

\begin{tabular}{|c|c|c|c|c|c|c|}
\hline \multirow{2}{*}{$\begin{array}{l}\text { Depth } \\
\text { (m) }\end{array}$} & \multicolumn{2}{|c|}{ Model silo 1} & \multirow{2}{*}{$\begin{array}{c}\text { Overpressure } \\
\text { coefficient }\end{array}$} & \multicolumn{2}{|c|}{ Model silo 2} & \multirow{2}{*}{$\begin{array}{c}\text { Overpressure } \\
\text { coefficient }\end{array}$} \\
\hline & $\begin{array}{l}\text { Static } \\
\text { pressure } \\
\text { of group } \\
\mathrm{A}(\mathrm{kPa})\end{array}$ & $\begin{array}{l}\text { Dynamic } \\
\text { pressure } \\
\text { of group } \\
\mathrm{A}(\mathrm{kPa})\end{array}$ & & $\begin{array}{l}\text { Static } \\
\text { pressure } \\
\text { of group } \\
\mathrm{A}(\mathrm{kPa})\end{array}$ & $\begin{array}{l}\text { Dynamic } \\
\text { pressure } \\
\text { of group A } \\
(\mathrm{kPa})\end{array}$ & \\
\hline 0.2 & 1.0689 & 1.6821 & 1.5735 & 1.0195 & 1.4187 & 1.3915 \\
\hline 0.4 & 1.6820 & 2.2587 & 1.3428 & 1.4499 & 2.5326 & 1.7466 \\
\hline 0.6 & 2.4270 & 2.5165 & 1.0368 & 1.8526 & 2.3755 & 1.2822 \\
\hline 0.8 & 3.1448 & 3.2925 & 1.0469 & 2.1961 & 2.4292 & 1.1061 \\
\hline 1 & 3.6157 & 4.2549 & 1.1767 & 2.4399 & 3.2931 & 1.3497 \\
\hline 1.1 & 3.9095 & 4.5232 & 1.1569 & 2.4560 & 3.4857 & 1.4192 \\
\hline
\end{tabular}


Table 2 The results of single side discharge of group $\mathrm{C}$ for two silo models

\begin{tabular}{|c|c|c|c|c|c|c|}
\hline \multirow{2}{*}{$\begin{array}{l}\text { Depth } \\
(\mathrm{m})\end{array}$} & \multicolumn{2}{|c|}{ Model silo 1} & \multirow{2}{*}{$\begin{array}{c}\text { Overpressure } \\
\text { coefficient }\end{array}$} & \multicolumn{2}{|c|}{ Model silo 2} & \multirow{2}{*}{$\begin{array}{c}\text { Overpressure } \\
\text { coefficient }\end{array}$} \\
\hline & $\begin{array}{l}\text { Static } \\
\text { pressure } \\
\text { of group } \\
\mathrm{C}(\mathrm{kPa})\end{array}$ & $\begin{array}{l}\text { Dynamic } \\
\text { pressure } \\
\text { of group } \\
\mathrm{C}(\mathrm{kPa})\end{array}$ & & $\begin{array}{l}\text { Static } \\
\text { pressure } \\
\text { of group } \\
\mathrm{C}(\mathrm{kPa})\end{array}$ & $\begin{array}{l}\text { Dynamic } \\
\text { pressure } \\
\text { of group } \\
\mathrm{C}(\mathrm{kPa})\end{array}$ & \\
\hline 0.2 & 1.0011 & 1.0462 & 1.0451 & 1.0370 & 1.3053 & 1.2588 \\
\hline 0.4 & 1.7043 & 1.7559 & 1.0302 & 1.6792 & 1.9240 & 1.1458 \\
\hline 0.6 & 2.4490 & 2.5407 & 1.0374 & 2.0402 & 2.6664 & 1.3069 \\
\hline 0.8 & 3.0641 & 3.2225 & 1.0517 & 2.2681 & 3.0210 & 1.3319 \\
\hline 1 & 3.6959 & 3.8047 & 1.0294 & 2.4162 & 2.7929 & 1.1558 \\
\hline 1.1 & 3.9664 & 4.0294 & 1.0158 & 2.5724 & 2.6139 & 1.0161 \\
\hline
\end{tabular}

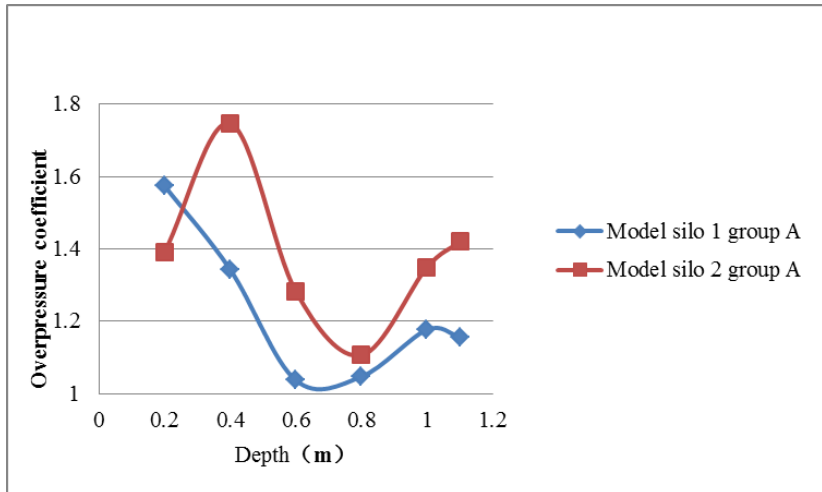

Fig.3 The curve of overpressure coefficient of single side discharge of group A for two silo models

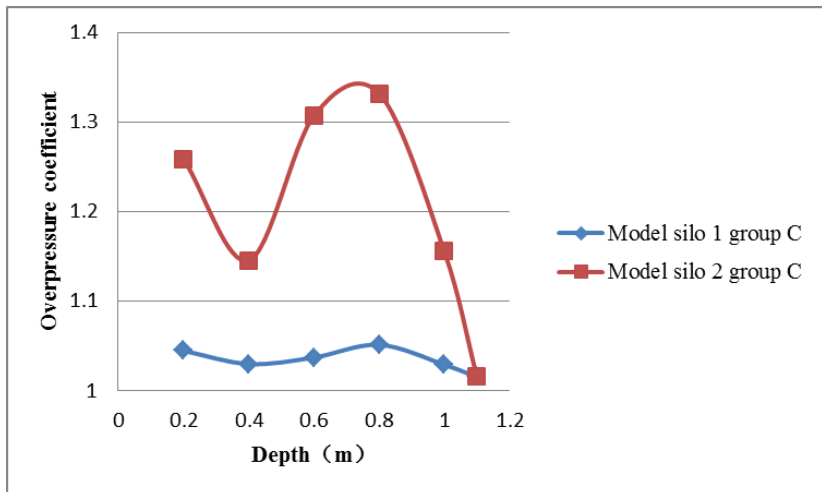

Fig.4 The curve of overpressure coefficient of single side discharge of group C for two silo models

The above graphs show the change curves of the overpressure coefficients of A\&C groups with the single-side discharging of which the cylinder walls had different height-diameter ratios. Where the abscissa indicates the depth of the measuring point, and the ordinate indicates the overpressure coefficient. From comparison of the overpressure coefficient curves in Fig. 3 and Fig. 4, where the discharge ports are located on the A side, the overpressure coefficients of the survey walls in two sets $\mathrm{A} \& \mathrm{C}$ in model 2 are generally larger than those in model 1 . Among them, the trend of the overpressure curve of the group $\mathrm{A}$ in model 2 can be divided into three stages, that is, the first increase and then decrease and then increase, dynamic side pressure gets a big change at the depth of $0.4 \mathrm{~m}$, where the maximum value of overpressure is 1.73 . The change trend of the overpressure coefficients corresponding to the six measuring points in the model 1 of group A can be divided into 
two stages: in the first stage, the measuring points are at the range of $0.2-0.6 \mathrm{~m}$, the overpressure coefficients decrease with the increasing of the depth, and at the $0.6 \mathrm{~m}$ depth reaches to the minimum; in the second stage, at the range of $0.6-1.1 \mathrm{~m}$, overpressure coefficients begin to increase gradually. The maximum overpressure coefficient appears at the depth of $0.2 \mathrm{~m}$ in the first stage with the value of 1.57. According to the comparison of A groups in different models, the maximum overpressure coefficient occurs at the upper part, and the flow pattern of the material begin to change from the whole flow to the tubular flow, which caused the local lateral pressure changed.

For the overpressure coefficient of group $\mathrm{C}$ for the two silo models, they have the similar variation trend of "decreasing, increasing and then decreasing", and both of them reach to the peak at depth of $0.8 \mathrm{~m}$ where the maximum values are 1.05 and 1.33 respectively. But the group $\mathrm{C}$ of silo model 1 has a more gradual trend and the dynamic side pressure of silo wall is without any great variation. Comparing with silo model 2 , the overpressure coefficients of group $\mathrm{C}$ for model silo 1 is far less. About the flow manners of two models, there exists obvious flowing and static area in model silo 1, while the material is first in overall flow and then turns into tubular flow at about 0.8 $\mathrm{m}$ in model silo 2 .

\section{Analysis on double side discharge test of the cylinder wall (different ratio of height to diameter)}

Table 3:The results of experiment $A$ about double side discharge of the silo wall.

\begin{tabular}{|c|c|c|c|c|c|c|}
\hline \multirow[t]{2}{*}{$\operatorname{Depth}(\mathrm{m})$} & \multicolumn{2}{|c|}{ Model silo 1} & \multirow{2}{*}{$\begin{array}{c}\text { Overpressure } \\
\text { coefficient }\end{array}$} & \multicolumn{2}{|c|}{ Model silo 2} & \multirow{2}{*}{$\begin{array}{c}\text { Overpressure } \\
\text { coefficient }\end{array}$} \\
\hline & $\begin{array}{l}\text { Static } \\
\text { pressure } \\
\text { of group } \\
\mathrm{A}(\mathrm{kPa})\end{array}$ & $\begin{array}{l}\text { Dynamic } \\
\text { pressure } \\
\text { of group } \\
\mathrm{A}(\mathrm{kPa})\end{array}$ & & $\begin{array}{l}\text { Static } \\
\text { pressure } \\
\text { of group } \\
\mathrm{A}(\mathrm{kPa})\end{array}$ & $\begin{array}{l}\text { Dynamic } \\
\text { pressure } \\
\text { of group } \\
\mathrm{A}(\mathrm{kPa})\end{array}$ & \\
\hline 0.2 & 0.9504 & 1.3258 & 1.3949 & 1.0261 & 1.0666 & 1.0395 \\
\hline 0.4 & 1.7723 & 2.2753 & 1.2838 & 1.4745 & 2.2439 & 1.5217 \\
\hline 0.6 & 2.564 & 2.6933 & 1.0504 & 1.9406 & 3.2607 & 1.58 \\
\hline 0.8 & 3.2330 & 3.3630 & 1.0402 & 2.3075 & 2.4121 & 1.0453 \\
\hline 1 & 3.8729 & 4.6731 & 1.2065 & 2.5323 & 4.0183 & 1.48 \\
\hline 1.1 & 3.9454 & 5.1879 & 1.3149 & 2.5176 & 4.1900 & 1.53 \\
\hline
\end{tabular}

Table 4:The results of experiment $\mathrm{C}$ about double side discharge of the silo wall.

\begin{tabular}{|c|c|c|c|c|c|c|}
\hline \multirow[t]{2}{*}{$\operatorname{Depth}(\mathrm{m})$} & \multicolumn{2}{|c|}{ Model silo 1} & \multirow{2}{*}{$\begin{array}{c}\text { Overpressure } \\
\text { coefficient }\end{array}$} & \multicolumn{2}{|c|}{ Model silo 2} & \multirow{2}{*}{$\begin{array}{c}\text { Overpressure } \\
\text { coefficient }\end{array}$} \\
\hline & $\begin{array}{l}\text { Static } \\
\text { pressure } \\
\text { of group } \\
\mathrm{C}(\mathrm{kPa})\end{array}$ & $\begin{array}{l}\text { Dynamic } \\
\text { pressure } \\
\text { of group } \\
\mathrm{C}(\mathrm{kPa})\end{array}$ & & $\begin{array}{l}\text { Static } \\
\text { pressure } \\
\text { of group } \\
\mathrm{C}(\mathrm{kPa})\end{array}$ & $\begin{array}{l}\text { Dynamic } \\
\text { pressure } \\
\text { of group } \\
\mathrm{C}(\mathrm{kPa})\end{array}$ & \\
\hline 0.2 & 0.9681 & 1.5716 & 1.51 & 1.0467 & 1.3071 & 1.2488 \\
\hline 0.4 & 1.8292 & 2.1104 & 1.1537 & 1.5556 & 2.4489 & 1.5741 \\
\hline 0.6 & 2.6730 & 2.7539 & 1.0302 & 2.0280 & 3.0116 & 1.4849 \\
\hline 0.8 & 3.279 & 3.4434 & 1.0501 & 2.2588 & 2.4365 & 1.0786 \\
\hline 1 & 3.7586 & 4.7522 & 1.2643 & 2.3212 & 3.3123 & 1.4269 \\
\hline 1.1 & 4.0268 & 4.7199 & 1.1721 & 2.5916 & 3.5115 & 1.3549 \\
\hline
\end{tabular}




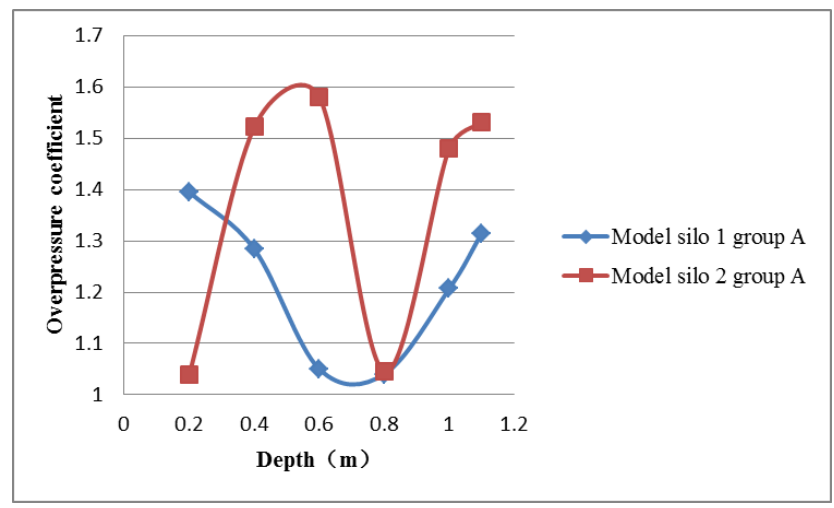

Fig.5 The overpressure coefficient curves of experiment A about double side discharge of the silo wall.

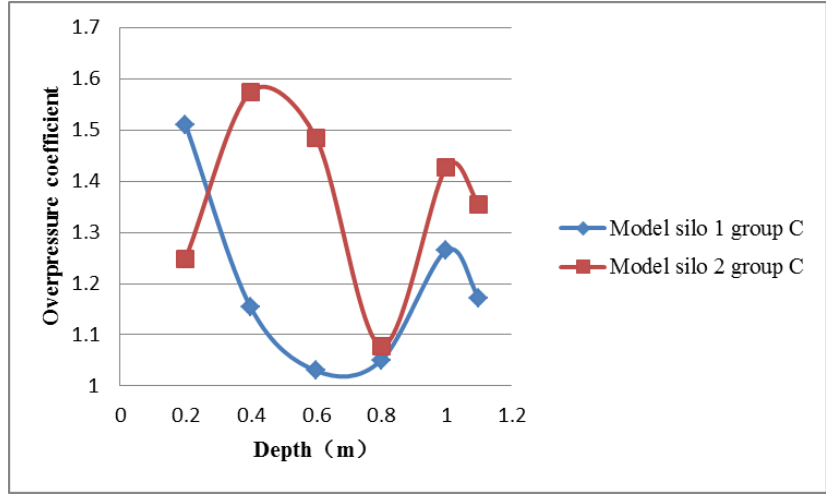

Fig.6 The overpressure coefficient curves of experiment $\mathrm{C}$ about double side discharge of the silo wall.

Two kinds of models with different height-diameter ratios to diameter named A and C are chosen, then the results of curves of over pressure coefficients are analyzed. The walls of $\mathrm{A}$ and $\mathrm{C}$ are symmetry and the discharge ports located in $\mathrm{A}$ and $\mathrm{C}$, the trend of over pressure coefficient curves are basically similar is found. (in Fig.5, Fig.6). Then, carrying contrast analysis about group A. In model silo 1, the maximum change value of dynamic lateral pressure occurs in the depth of $0.2 \mathrm{~m}$, which the maximum over pressure coefficient is 1.39 , the variation trend of the over pressure coefficient can be divided into two stages, in the range of $0.2-0.7 \mathrm{~m}$, the over pressure coefficient at each measuring point decreases with the increase of the depth of the silo, in the range of $0.7-1.1 \mathrm{~m}$, the over pressure coefficient of each measuring point begin to increase. Based on the comparison of the over pressure coefficients of the two models in group A, the majority values of over pressure coefficients of model 1 at measurement points are far less than those in model 2, and the fluctuation of over pressure coefficients are from 1.04 to 1.39. The variation curves of the over pressure coefficients at each measuring point in model 2 can be divided into three stages: first period, in $0.2-0.6 \mathrm{~m}$, the value of over pressure coefficients increase with the increasing of depth, and reaches the maximum value of 1.58 at $0.6 \mathrm{~m}$; second period, in $0.6-0.8 \mathrm{~m}$, each point of over pressure value begins to decrease, reaches to the lowest level at $0.8 \mathrm{~m}$; thirdly, in $0.8-1.1 \mathrm{~m}$, it increases with the depth of the silo with the fluctuation range of 1.03-1.53. Based on the comparison of the flow pattern of the two models, the location of the maximum over pressure coefficients occur when the overall flow mode begin to change to the tubular flow mode.

\section{Conclusion}

Using the storage of wheat as the object, through the scale model test, this paper comparatively studies on the influence of the dynamic lateral pressure changes and over-pressure coefficients of 
material in warehouse in two models of different height-diameter ratio silo, and the results are as follows:

(1)Model silo 1, which has smaller height-diameter ratio, the overall overpressure coefficients of two side walls are generally lower than the model silo 2. Among then, A walls at the same side of the discharge ports have the same change tendency in models with different height-diameter ratios, which only affect the numerical value, overpressure coefficients of each measuring point of $\mathrm{C}$ walls which far from discharge ports, in the model silo1, dynamic lateral pressure changes gently, the fluctuation amplitude is small, about 1.03 - 1.05; in the model silo 2 with height-diameter ratio, dynamic lateral pressure changes drastic with fluctuation in the magnitude of 1.01-1.33.

(2)According to the double side discharge test, through the comparison of the data, the overall overpressure coefficients of the model silo 1 is generally lower than the model silo2.

(3)Through the comparison of overpressure coefficient curves in A\&C groups of the two models with different height-diameter ratios, this paper found the height-diameter ratio of the model warehouse affects the flow pattern of the stored material in the silo, and changes the dynamic lateral pressure of the silo wall in the process of dynamic unloading. It is easily to produce mixed flow mode thus the over-pressure phenomenon is obvious in area when the whole flow transforms to the tubular flow.

\section{Acknowledgments}

The authors appreciate the support of the National Science Foundation of China(No. 51578216, 51608177), and the He'nan University of Technology Fund Project for high-level talents(2013BS010)

\section{References:}

[1] Qipeng Cheng,Weiwei Sun,Sai Lu. Discrete Element Analysis of Squat Silo Under Eccentric Discharge by PFC3D [J]. Journal of Civil Engineering and Management,2016,(06):43-47. (In Chinese)

[2] Song Zhao. Analysis and Application for Silo Storage Pressure[D]. Wuhan University of Technology,2013. (In Chinese)

[3] Jianhua Wang,Dinghua Liu,Jianbin Yang. On the Stored Material Lateral Pressures of a New TyPe of Silo in Silo [J]. Journal of Xian University of Architecture \& Technology(Natural Science Edition),1993,(02):227-232. (In Chinese)

[4] Jvxain Tu,Jianbin Yang. The Model Experiments of Silo for Unloading Condition and Pressure of the Silo Wall Calculation [J]. Journal of Yantai University (Natural Science and Engineering),1998,(03):212-217. (In Chinese)

[5] Jvxian Tu,Zhenbin Cao. Analysis of Flow Form of Stored Materials and Pressure of Silo Wall [J]. Mechanic`s in Engineering,1998,(05):20-24. (In Chinese)

[6] C. J. Brown., E. H. Lahlouh and J. M. Rotter. Experiments on a Square Plan form Steel Silo.

Chemical Engineering Science, 2000, 55: 4399-4413.

[7] Zhenyv Zhang,Qingwang Fu. Inner force analysis of large diameter concrete silo wall[J]. Coal Engineering,2016,(01):43-45+48. (In Chinese) 